\title{
Musculoskeletal Response to Whole-Body Vibration During Fracture Healing in Intact and Ovariectomized Rats
}

\author{
Ewa K. Stuermer • Marina Komrakova Carsten Werner • Michael Wicke • \\ Leila Kolios • Stephan Sehmisch • Mohammad Tezval • Clara Utesch • \\ Orzala Mangal · Sebastian Zimmer · Christian Dullin · Klaus M. Stuermer
}

Received: 31 March 2010/ Accepted: 13 May 2010/Published online: 9 June 2010

(c) The Author(s) 2010. This article is published with open access at Springerlink.com

\begin{abstract}
This study investigated the effect of vibration on bone healing and muscle in intact and ovariectomized rats. Thirty ovariectomized (at 3 months of age) and 30 intact 5-month old female Sprague-Dawley rats underwent bilateral metaphyseal osteotomy of tibia. Five days later, half of the ovariectomized and of the intact rats were exposed to whole-body vertical vibration $(90 \mathrm{~Hz}, 0.5 \mathrm{~mm}$, $4 \times g$ acceleration) for $15 \mathrm{~min}$ twice a day during 30 days. The other animals did not undergo vibration. After decapitation of rats, one tibia was used for computed tomographic, biomechanical, and histological analyses; the other was used for gene expression analyses of alkaline phosphatase (Alp), osteocalcin (Oc), tartrate-resistant acid phosphatase 1, and insulinlike growth factor 1. Serum Alp
\end{abstract}

E. K. Stuermer and M. Komrakova contributed equally to this study. The authors have stated that they have no conflict of interest.

E. K. Stuermer · M. Komrakova $(\bowtie) \cdot$ L. Kolios .

S. Sehmisch · M. Tezval · C. Utesch · O. Mangal ·

S. Zimmer - K. M. Stuermer

Department of Trauma Surgery and Reconstructive Surgery,

University of Goettingen, Robert-Koch St. 40, 37075

Goettingen, Germany

e-mail: komrakova@yahoo.com

C. Werner

Institute of Food Quality and Safety, University of Animal

Medicine, Hannover, Germany

M. Wicke

Department of Animal Sciences, University of Goettingen, Goettingen, Germany

C. Dullin

Department of Radiology, University of Goettingen, Goettingen, Germany and Oc were measured. Mitochondrial activity, fiber area and distribution, and capillary densities were analyzed in $M$. gastrocnemius and $M$. longissimus. We found that vibration had no effect on body weight and food intake, but it improved cortical and callus densities ( 97 vs. $99 \%, 72$ vs. $81 \%$ ), trabecular structure ( 9 vs. 14 trabecular nodes), blood supply (1.7 vs. 2.1 capillaries/fiber), and oxidative metabolism (17 vs. 23 pmol $\mathrm{O}_{2} / \mathrm{s} / \mathrm{mg}$ ) in ovariectomized rats. Vibration generally increased muscle fiber size. Tibia biomechanical properties were diminished after vibration. Oc gene expression was higher in vibrated rats. Serum Alp was increased in ovariectomized rats. In ovariectomized rats, vibration resulted in an earlier bridging; in intact rats, callus bridging occurred later after vibration. The chosen vibration regimen $(90 \mathrm{~Hz}, 0.5 \mathrm{~mm}, 4 \times g$ acceleration, 15 min twice a day) was effective in improving musculoskeletal tissues in ovariectomized rats but was not optimal for fracture healing.

Keywords Whole-body vibration - Osteoporosis . Fracture healing $\cdot$ Muscle $\cdot$ Ovariectomized rat

Healing of bone fracture greatly depends on the mechanical conditions at the fracture site. In clinical situations, the period between injury and the time at which weight bearing is commenced is often delayed. Moreover, severe osteopenia and muscle atrophy may develop under conditions of immobilization in humans and animals [1, 2]. In immobile patients, lack of adequate mechanical stimulus is considered to be a reason for insufficient callus formation and delayed healing. Micromovements at the fracture site have been shown to stimulate new bone formation [3, 4]. Besides mechanical stimulation, estrogen plays an important role in a fracture healing. In animals with estrogen 
deficiency, delayed fracture healing and slowed muscle recovery after inactivity have been observed $[5,6]$.

Evidence in animals and humans indicates that brief exposure to low-magnitude, high-frequency mechanical signals of 10 to $100 \mathrm{~Hz}$ at $<0.5 \times g$ acceleration beneficially affects the musculoskeletal system $[7,8]$. In postmenopausal women, vibrations $(35-40 \mathrm{~Hz}, 2-5 \times g$ acceleration) were able to increase hip bone mineral density and improved muscle strength [9]. Vibrations (17$45 \mathrm{~Hz}, 0.5-3 \times g$ acceleration) applied in ovariectomized rats were anabolic to bone, whereas in intact animals, there was no bone response $[10,11]$. The increase in the vibration frequency from 45 to $90 \mathrm{~Hz}$ resulted in a larger trabecular and cortical bone formation rates in the tibia metaphysis of ovariectomized rats [7].

The physical mechanisms by which bone cell responds to whole-body vibration, with a preference toward certain vibration frequencies, have not yet been identified. Different mechanical stimuli can either provide effective augmentation of fracture healing and bone regeneration or maturation, or delay these processes [12]. As in muscle, mechanical stimulation may have beneficial or adverse effects on musculature $[8,13]$. Previous studies on induced mechanical stimulation during fracture healing differ in the type of fixators and strains (tensional or compressional), with a stimulation unit temporally attached to the bone fixator. Externally induced short-term, cyclical interfragmentary movements of $1 \mathrm{~Hz}(1-0.5 \mathrm{~mm})$ were shown to enhance bone healing process if applied to osteotomies stabilized by rigid external fixators [14-16]. This effect was not observed when a flexible external fixator was used $[17,18]$.

Stimulation of bone healing with whole-body vibration allows such stimulation to be noninvasively applied to fractures, regardless of the type of fixators used. Wolf et al., who investigated the effect of whole-body vibration $(20 \mathrm{~Hz} ; 5 \mathrm{~min}$ per day) on fracture of externally fixed ovine metatarsus, found no improvement in bone healing [19]. In contrast, a beneficial effect on fracture healing by the vibration of $25 \mathrm{~Hz}$ (60 min per day) in rabbit fibula [20] and by the $35 \mathrm{~Hz}$ vibration (20 min per day) in rat femora [21] has been reported. These studies were performed on skeletally mature and intact females and are restricted to the bone-healing processes, whereas the effect of the vibration on the muscle during fracture healing remained unknown. Because vibration primarily evokes reflexive muscle contractions that mechanically load the bone, investigation of both muscle and bone tissues is important. Furthermore, osteoporosis remarkably delays fracture healing [5], and whole-body vibration may augment the healing processes.

In the present study, we investigated the effect of wholebody vibration on bone healing and muscle function in intact and ovariectomized rats.

\section{Materials and Methods}

Sixty 3-month-old female Sprague-Dawley rats were obtained from Harlan Winkelmann (Borchen, Germany). Thirty rats were bilaterally ovariectomized under intraperitoneal ketamine (Medistar, Holzwickede, Germany) and xylazine (Riemser, Greifswald-Insel Riems, Germany) anesthesia (40 and $10 \mathrm{mg} / \mathrm{kg}$ body weight, respectively). The remaining 30 rats were left intact. Rats were housed four to five animals per standard cage under 12-h darklight photoperiods at a constant temperature of $22 \pm 1{ }^{\circ} \mathrm{C}$. After 10 weeks, when ovariectomized animals developed severe osteopenia [22], all 60 animals underwent a bilateral transverse osteotomy of tibia in the metaphysis [23]. Both tibiae of ketamine- and xylazine-anesthetized rats were osteotomized $7 \mathrm{~mm}$ distal to the knee surface with a pulsed ultrasound saw (Piezosurgery, Mectron Medical Technology, Carasco, Italy). A 1-mm osteotomy gap was generated, and a five-hole, T-shaped titan plate (Stryker Trauma, Selzach, Switzerland) was fixed to the ventromedial aspect of the tibia. Plate fixation was performed in a bridging technique with the aid of four screws [23].

Five days after osteotomy, half the ovariectomized and intact rats were exposed to whole-body vertical vibration with $90 \mathrm{~Hz}$ frequency, $0.5-\mathrm{mm}$ amplitude, and $4 \times g$ acceleration measured with the aid of SWM 3000 instrument (REO Elektronik, Berlin, Germany). Rats were transferred 10 at a time to the plastic cage (Fig. 1a) and underwent vibration for $15 \mathrm{~min}$ twice a day for 30 days. The other animals did not undergo vibration. Vibration was performed via a newly developed vibration device (Vibra Maschinenfabrik Schultheis, Offenbach, Germany) consisting of a vibration desk, two alternating current engines, and a force transducer for monitoring the frequency of vibration (Fig. 1b-d). A plastic cage $\left(50 \times 50 \times 25 \mathrm{~cm}^{3}\right)$ was attached to the vibration desk to maintain the rats during vibration sessions (Fig. 1a).

All rats received a standard pellet diet (Ssniff Special Diet, Soest, Germany) throughout the experiment. Animals were weighed weekly during experiment. The daily food intake was calculated on the basis of a weekly weighing of food after osteotomy onward. All animals had free access to food and water and were allowed to freely move within the cages at all times.

After 35 days of fracture healing, rats were decapitated under carbon dioxide anesthesia. Blood samples were collected and centrifuged, and serum was stored at $-20^{\circ} \mathrm{C}$ until electrochemiluminiscence immunoassay analyses of osteocalcin and colorimetric assay of alkaline phosphatase (Alp) could be conducted. Serum analyses were conducted at the Department of Clinical Chemistry, University of Goettingen, with a automated chemistry analyzer (Roche/ Hitachi Modular) according to the manufacturer's 


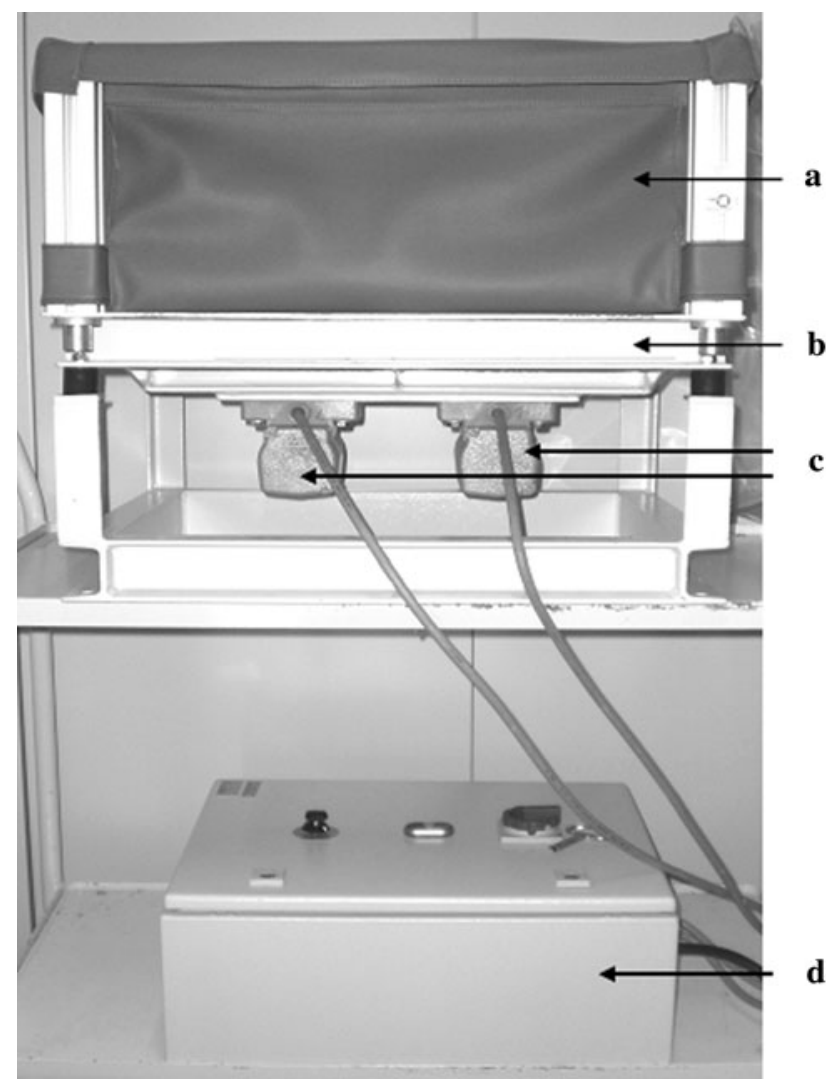

Fig. 1 Vibration device a cage for rats; b vibration desk; c two engines; $\mathbf{d}$ force transducer

instructions (Roche Diagnostics, Mannheim, Germany). The uterus was extracted and weighed. Muscle samples were collected from M. gastrocnemius (MG) and M. longissimus (ML), randomized left or right. From the middle part of the MG, a piece of muscle (approximately $80 \mathrm{mg}$ ) was immersed in ice-cold storage medium, $\mathrm{pH} \mathrm{7.1,} \mathrm{for} \mathrm{up}$ to $4 \mathrm{~h}$ before respirometric measurements were performed [24]. A block of muscle $\left(1 \mathrm{~cm}^{3}\right)$ from MG and ML was frozen directly in liquid nitrogen to be stored at $-80^{\circ} \mathrm{C}$ until histological analysis.

Left and right tibiae were dissected free of soft tissues. The plate and screws were carefully extracted. One tibia chosen randomly was stored at $-20^{\circ} \mathrm{C}$ until use in computed tomographic, biomechanical, histological, and microradiographic analyses. Metaphyseal clips of other tibia with a newly formed callus at the osteotomy line were placed in liquid nitrogen and then stored at $-80^{\circ} \mathrm{C}$ for gene expression analyses.

All chemicals were obtained from Sigma-Aldrich Chemie, Taufkirchen, Germany, unless otherwise indicated.

The animal study protocol was approved by the local regional government and conformed to German animal protection laws (permission from December 21, 2006, Az 33.42502-04-011/07, District Government of Braunschweig).
Bone Analyses

\section{Bone Labeling}

The labeling of new bone formation was performed in vivo with fluorescent dyes injected subcutaneously [25]. Xylenol orange ( $90 \mathrm{mg} / \mathrm{kg}$ body weight) was injected on day 13 , calcein green $(10 \mathrm{mg} / \mathrm{kg}$ body weight) on day 18 , and alizarin complexone $(30 \mathrm{mg} / \mathrm{kg}$ body weight) on day 24 and 26 after osteotomy, respectively. The injection of alizarin complexone was repeated to intensify labeling. Tetracycline $(25 \mathrm{mg} / \mathrm{kg}$ body weight) was injected $1 \mathrm{~h}$ before decapitation, i.e., 35 days after osteotomy.

\section{Gene Expression Analyses}

Total cellular RNA was extracted as previously reported [26]. Briefly, tissues were homogenized and RNA was extracted using the RNeasy Mini Kit (Qiagen, Hilden, Germany). RNA concentration was measured with the aid of a photometer (Biometra, Goettingen, Germany). Diluted RNA (5 $\mathrm{ng} / \mu \mathrm{l})$ was stored at $-80^{\circ} \mathrm{C}$ until usage. The RNA samples (50 ng) were then reverse transcribed using Superscript RNase H-reverse transcriptase (Promega, Mannheim, Germany). Expression of the rat genes, Alp, osteocalcin (Oc), tartrate-resistant acid phosphatase 1 (Trap-1), and insulin-like growth factor 1 (Igf-1) was determined by quantitative real-time polymerase chain reaction (qRT-PCR) based on SYBR Green detection using iCycler (iQ-System; Bio-Rad Laboratories, Munich, Germany). Ready-to-use primer pairs were obtained from Qiagen (QuantiTect Primer Assays). The qRT-PCR was carried out according to the manufacturer's protocols (Qiagen). Relative gene expression was calculated by the $2^{-\Delta \Delta \mathrm{CT}}$ method [27] for each gene of interest, where $\Delta \Delta \mathrm{C}_{\mathrm{T}}=\left(\mathrm{C}_{\mathrm{T}}\right.$ treatment group gene $-\mathrm{C}_{\mathrm{T}} 18 \mathrm{~S}$ rRNA $)-$ $\left(\mathrm{C}_{\mathrm{T}}\right.$ intact nonvibrated gene $-\mathrm{C}_{\mathrm{T}} 18 \mathrm{~S}$ rRNA). Gene expression in intact nonvibrated group was taken as 1 .

\section{Flat-Panel Volume Computed Tomography}

Tibia were thawed and analyzed by means of flat-panel detector-based volume computer tomography (fpVCT; GE Global Research, Niskayuna, NY), a nonclinical computed tomography prototype [28]. The measurements were performed with a single flat-panel detector consisting of 1024 by 1024 detector elements with an element size of $200 \times 200 \mu \mathrm{m}$. The X-ray source was operated at $80 \mathrm{kVp}$ with anode current of $100 \mathrm{~mA}$. Samples were scanned with a step-and-shoot acquisition protocol with 500 projection images per full rotation within $4 \mathrm{~s}$. The spatial resolution of the system is approximately $200 \mu \mathrm{m}$ at $10 \%$ modulation transfer function. All data were reconstructed with a voxel 
size of $100 \mu \mathrm{m}$ and were analyzed on an Advantage workstation (version 4.2; General Electric Health Care, Milwaukee, WI). The measurement area extended $1.5 \mathrm{~mm}$ proximally and $1.5 \mathrm{~mm}$ distally from the osteotomy site (Fig. 2a, b; Fig. 3). Total, callus, and cortical densities were measured within the 3-D region of interest and initially assessed in Hounsfield units, then converted into bone mineral density $\left(\mathrm{mg} / \mathrm{cm}^{3}\right)$ by a linear regression equation (bone mineral density $=0.3385 \times$ value in Hounsfield units +33.321 ) that was formulated measuring three hydroxyapatite standards of several mineral densities. The total area and the callus and cortical areas were measured $\left(\mathrm{mm}^{2}\right)$ on 2-D images of three longitudinal sections (200- $\mu \mathrm{m}$ thickness) made similar to those studied in histological analyses.
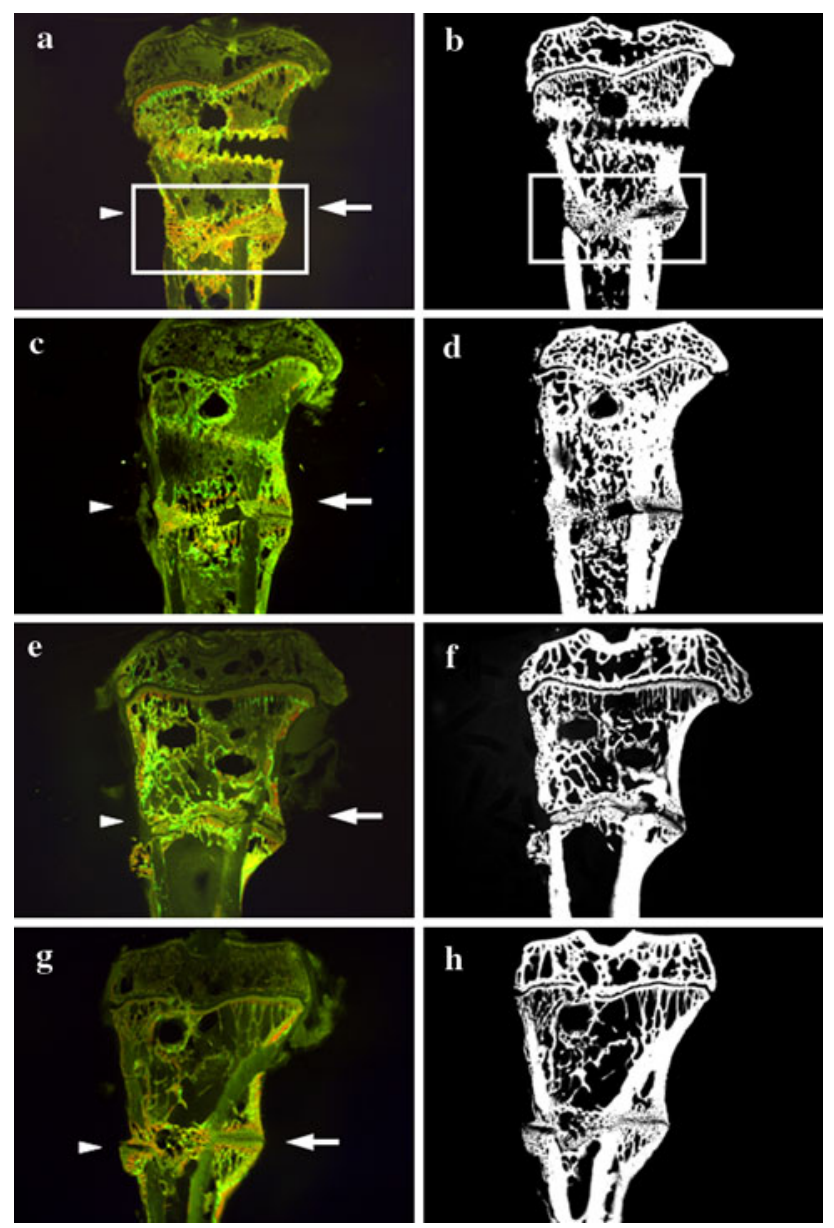

Fig. 2 Computed images of the metaphysis of tibia longitudinal sections labeled intravital with fluorochromes and the corresponding microradiographs made after 35 days of osteotomy healing in $\mathbf{a}, \mathbf{b}$ intact non-vibrated (vib); (c, d) intact vib; e, f ovariectomized (Ovx) non-vib; and $\mathbf{g}, \mathbf{h}$ Ovx vib rats. Arrowheads, ventromedial aspect; arrows, dorsal aspect; rectangular frame, region of interest

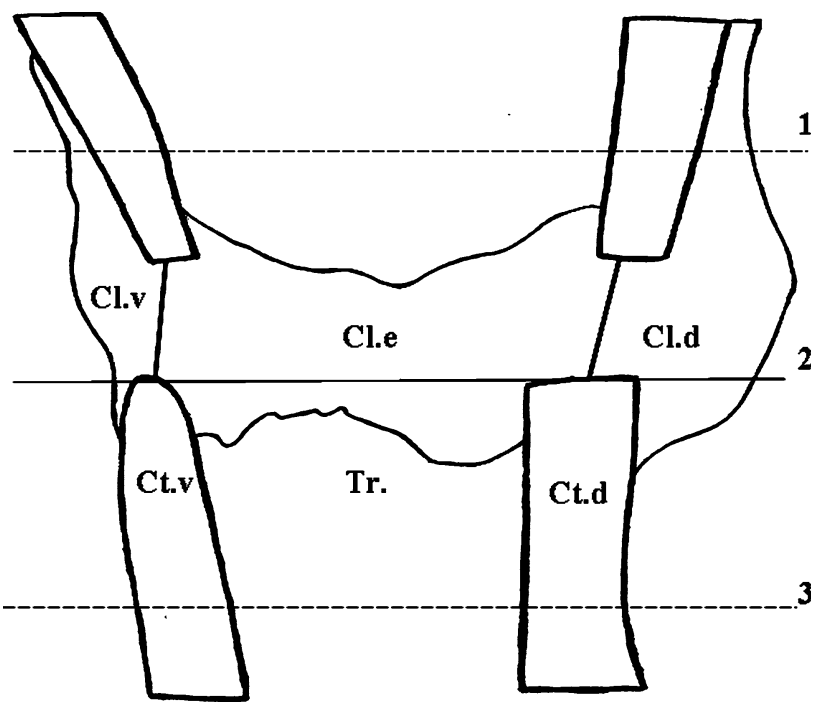

Fig. 3 Schematic diagram of measurement areas (1.5 mm proximally and distally from the osteotomy line). 1, proximal margin; 2, alignment line; 3, distal margin; Cl.v, callus ventromedial; Cl.e, callus endosteal; Cl.d, callus dorsal; Ct.v, cortical bone ventromedial; Ct.d, cortical bone dorsal; Tr., area of trabecular measurements

\section{Biomechanical Analyses}

Stiffness of the tibia was evaluated by a three-point bending test [29] that used a testing machine (type 145660 Z020/TND; Zwick/Roell, Ulm, Germany). Tibia were loaded at the osteotomy line of the ventromedial aspect. After applying a preload of $1 \mathrm{~N}$, nondestructive measurements were performed at a feed motion rate of $5 \mathrm{~mm} / \mathrm{min}$ by testXpert software (Zwick/Roell, Ulm, Germany). The measurements were stopped when elastic deformation reached yield point. The stiffness $(\mathrm{N} / \mathrm{mm})$ was defined as a slope of the linear rise of the curve and was calculated by the Excel computer program (Microsoft, Redmond, WA).

\section{Histological Analyses}

The entire tibia was subjected to the sequential ascending concentrations of ethanol and embedded in methylmethacrylate (Merck). Longitudinal sections $150 \mu \mathrm{m}$ thick were cut at the right angle to the ventromedial aspect of tibia with a Leica SP 1600 diamond saw microtome (Leica Instruments, Nussloch, Germany). The earliest callus bridging of the osteotomy gap was determined by analyzing at least 10 fluorochrome-labeled sections. Three central representative sections were microradiographed with the aid of the Faxitron Cabinet $x$-ray system using Kodak Industrex film (SR 45, 100 NIF, Kodak, Paris, France) at a resolution of $0.5 \mu \mathrm{m}$ and exposure of $0.2 \mathrm{~mA}$ for $3 \mathrm{~min}$. The sections and the corresponding microradiographs were digitized with a digital camera (Leica DC300F) and zoom stereo microscope (Leica MZ75) at a magnification of $\times 16$ 
with the aid of QWin image analysis program (Leica, Bensheim, Germany).

The osteotomy gap was divided into three regions of interest: (1) plate side, ventromedial aspect; (2) dorsal aspect; and (3) the endosteal part of the tibia. Alignment line was set on the osteotomized ends of distal cortical bone, enabling comparable measurements of the sections (Fig. 3, line 2). The measurement area extended $1.5 \mathrm{~mm}$ proximally and distally from the alignment line, similar to that analyzed in the fpVCT data sets (Fig. 3, lines 1 and 3). Cortical width and density distal to osteotomy, periosteal callus width and density, endosteal callus density, number of trabecular nodes, and trabecular width were measured via microradiographs (Fig. 3). The areas of newly built callus were determined by analyses of fluorochromelabeled sections according to the period of callus formation. The rate of callus formation was determined dividing the labeled callus area $\left(\mu \mathrm{m}^{2}\right)$ by labeling-specific days [30]. The green-stained area was built during 5 days (within 13 and 18 days after fracture), red-stained tissue during 8 days (from 18 to 26 days), and yellow-stained area during 9 days (26-35 days after fracture). The xylenol orangelabeled area was too small to be measured adequately and therefore was not included in the analyses.

\section{Muscle Analyses}

\section{Respirometric Measurements}

Respirometric measurements were performed as described previously [24]. Samples of MG were dissected, permeabilized in saponin supplemented storage medium $(50 \mu \mathrm{g} /$ $\mathrm{ml}$ ), and washed three times for 15 min each in incubation medium ( $\mathrm{pH}$ 7.4). The mitochondrial respiratory activity of the permeabilized muscle fibers was analyzed with an oxygraph (Oroboros, Innsbruck, Austria). The weight specific oxygen consumption rate ( $\mathrm{pmol} \mathrm{O}_{2} \mathrm{~s} / \mathrm{mg}$ of sample weight) was measured with substrates: $9.5 \mathrm{mM}$ pyruvate and $1.9 \mathrm{mM}$ malate in the presence of $5 \mathrm{mM}$ adenosine triphosphate (state 3) and $26 \mu \mathrm{M}$ carboxyatractyloside (state 4) with the aid of DatLab 4.0 analysis software (Oroboros). Physiological respiratory activity of mitochondria was estimated by calculating the respiratory control ratio, defined as state 3 respiration rate divided by state 4 respiration rate. At least nine replications per treatment group were performed.

\section{Histological Analyses}

Analyses were performed as described previously [24]. Serial cross sections of $12 \mu \mathrm{m}$ were cut in a cryostat (Leica) and mounted on glass slides. For the analysis of muscle fibers, sections were fixed in $1 \%$ paraformaldehyde solution ( $\mathrm{pH} \mathrm{6.6)} \mathrm{and} \mathrm{thereafter} \mathrm{stained} \mathrm{for} \mathrm{reduced} \mathrm{nico-}$ tinamide adenine dinucleotide diaphorase activity ( $\mathrm{pH}$ 7.4) and calcium-activated myofibrillar adenosine triphosphatase activity ( $\mathrm{pH} 9.4)$ after acidic preincubation $(\mathrm{pH} 4.2$ ). Representative sections were used for final measurements of muscle fibers classified according to Peter et al. [31]. Fast-twitch glycolytic fibers and fast-twitch oxidative glycolytic fibers were measured. Because slow oxidative fibers were rarely represented and cannot always be clearly distinguished from fast-twitch oxidative glycolytic fibers, they were included in the analyses of fast-twitch oxidative glycolytic. At least 60 fibers of each fiber type per rat were typed and measured in each muscle. Fiber type distribution was determined in three randomly selected fields $\left(1 \mathrm{~mm}^{2}\right.$ each) from the ML section. For the analysis of blood capillaries, the periodic acid-Schiff staining method was applied. Capillaries and fibers found in three randomly selected fields $\left(1 \mathrm{~mm}^{2}\right.$ each) from the MG and ML sections were counted. The ratio of capillaries to muscle fiber was taken in the analysis. At least nine replications per treatment group were performed.

\section{Statistical Analyses}

Analysis of variance $(F$-test, $P<0.05)$ was applied to reveal the impact of the fixed effects vibration, ovariectomy, duration of the treatment (for food intake and body weight) and their interactions on the respective variables (SAS version 9.0; SAS Institute, Cary, NC). Significant interactions between the effects are indicated in the Results. The weight of the rats was taken as a covariate to examine its effect on the variables. The effect was insignificant $(P>0.05, F$-test $)$. Differences between individual means were estimated by the Scheffé test $(P<0.05)$. Data are shown as means and standard errors of the mean. Nonparametric Kruskal-Wallis test and Dunn multiple comparison test were used for analyses of gene expression (GraphPad Prism 4.0; GraphPad Software, San Diego, CA).

\section{Results}

During the experiment, two rats in the nonvibrated group died, one ovariectomized and one intact. After osteotomy, rats resumed normal movement within a few hours after recovering from anesthesia. However, some reduction in physical activity of the rats was observed subjectively during the first 2-3 days after osteotomy.

Fibulae were examined for the presence of fractures by means of 3-D images made by fpVCT. In ovariectomized rats, the fibula was fractured in four vibrated and three nonvibrated rats. In intact rats, fibula was fractured in six 
vibrated and three nonvibrated rats, respectively. These animals were not included in the analyses because of the different mechanical environment at the fracture site.

\section{Body Weight and Food Intake}

Vibration had no significant effect on the body weight of the rats $(P>0.05)$. Ovariectomy significantly increased body weight of the animals compared to that of the intact animals even after the first week $(P<0.05)$. During the first 4 weeks after ovariectomy (week 0 ), the body weight of the ovariectomized rats increased sharply $(P<0.001)$ from $225 \pm 2.5 \mathrm{~g}$ up to $334 \pm 6.2 \mathrm{~g}$. Thereafter, the rate of body weight increase slowed, reaching its maximum at week $10(368 \pm 6.5 \mathrm{~g})$ when osteotomy was conducted. However, the body weight of intact animals did not increase as rapidly, from $225 \pm 2.2 \mathrm{~g}$ at the beginning to $303 \pm 4.5 \mathrm{~g}$ after 10 weeks. After osteotomy (week 10), a slight decrease in body weight was observed in all groups. However, it recovered to the level measured at osteotomy to the end of the experiment.

Neither vibration nor ovariectomy affected the rats' food intake during vibration treatments $(P>0.05)$. At 5 weeks after osteotomy, daily food intake was not different between the groups, averaging $17 \pm 1 \mathrm{~g}$ per rat among the groups.

\section{Uterus Weight}

The effect of ovariectomy on uterus weight was highly significant $(P<0.001)$, whereas vibration had no effect $(P>0.05)$. Uterus weight in ovariectomized animals was in average $0.10 \pm 0.01 \mathrm{~g}(n=29)$, and in intact animals averaged $0.57 \pm 0.03 \mathrm{~g}(n=29)$.

\section{Serum Analyses}

Ovariectomy significantly increased serum concentration of Alp (Table 1). The effect of vibration on Alp level was negligible $(P>0.05)$. Serum concentration of Oc did not differ significantly between the treatment groups (Table 1).

\section{Bone Analyses}

\section{Gene Expression Analyses}

Osteocalcin gene expression was significantly higher in vibrated intact and ovariectomized rats compared to that in the ovariectomized nonvibrated group (Fig. 4a). Neither ovariectomy nor vibration had significant effect on the expression levels of other genes (Alp, Igf-1, and Trap-1) determined in the callus after 35 days of fracture healing (Fig. 4b-d).

\section{fpVCT Analyses}

fpVCT analyses revealed significant effects of ovariectomy on bone and callus parameters. The vibration had less effect $(P>0.05)$. Cortical area, cortical density, and total bone density were significantly impaired in ovariectomized animals compared with those in intact rats (Table 1). In contrast, the callus area was significantly larger in ovariectomized animals compared to that in intact rats, whereas callus density did not differ between these groups.

\section{Biomechanical Analyses}

Stiffness of the callus was affected by the vibration, whereas ovariectomy had no effect (Table 2). The vibration reduced callus stiffness significantly in intact rats (from 138 to $78 \mathrm{~N} / \mathrm{mm}$ ). The reduction was also observed in ovariectomized rats (from 122 to $85 \mathrm{~N} / \mathrm{mm}$ ), but it was not significant. A similar tendency was observed for the yield load, although the differences between the treatment groups were insignificant (Table 1).

\section{Histological Analyses}

Qualitative analyses of fracture healing showed that after 35 days of fracture healing, bone healing was not complete, and osteotomy could be clearly observed in all groups (Fig. 2a-h). Osseous callus bridging was observed in all rats. In ovariectomized rats that were vibrated, the earliest bridging occurred after 18 days of healing in average. In nonvibrated ovariectomized rats, the bridging was observed after 22 days of healing. In intact rats that were vibrated and not vibrated, fracture gap was bridged after 25 and 20 days on average, respectively.

Quantitative analyses of microradiographic images of histological sections revealed significant effect of vibration on cortical density at the ventromedial aspect, improving it in ovariectomized rats $(P<0.05)$. Slight, although not statistically significant, improvement was observed in callus density and trabecular number and width in ovariectomized rats that were vibrated (Table 1). Ovariectomy resulted in a significant decrease of cortical and callus densities at the ventromedial aspect and of number of trabecular nodes. Periosteal callus width was not changed ventromedially. At the dorsal aspect, periosteal callus width was increased in ovariectomized rats compared with that in intact rats, whereas the density was significantly lower in these rats. The interactions between two factors (ovariectomy and vibration) had significant effect on cortical width at the dorsal aspect and on endosteal callus density. Cortical width was decreased in ovariectomized rats, whereas in intact rats it remained unchanged. The vibration lowered endosteal callus density in intact rats, 
Table 1 Analyses of tibia performed on day 35 after osteotomy in ovariectomized and intact rats

\begin{tabular}{|c|c|c|c|c|c|c|c|c|}
\hline \multirow[t]{3}{*}{ Parameter } & \multicolumn{4}{|c|}{ Ovariectomized } & \multicolumn{4}{|l|}{ Intact } \\
\hline & \multicolumn{2}{|c|}{ Vibrated } & \multicolumn{2}{|c|}{ Not vibrated } & \multicolumn{2}{|c|}{ Vibrate } & \multicolumn{2}{|c|}{ Not vibrated } \\
\hline & Mean & SEM & Mean & SEM & Mean & SEM & Mean & SEM \\
\hline \multicolumn{9}{|l|}{ Analyses } \\
\hline \multicolumn{9}{|l|}{ Serum analyses } \\
\hline Alp (U/1) & $64^{\mathrm{A}}$ & 5 & $63^{\mathrm{AC}}$ & 4 & $47^{\mathrm{B}}$ & 3 & $52^{\mathrm{BC}}$ & 5 \\
\hline $\mathrm{Oc}(\mu \mathrm{g} / \mathrm{l})$ & 27 & 4 & 21 & 2 & 19 & 2 & 22 & 2 \\
\hline \multicolumn{9}{|l|}{ fpVCT analyses } \\
\hline Cortical area $\left(\mathrm{mm}^{2}\right)$ & $0.9^{\mathrm{A}}$ & 0.1 & $0.8^{\mathrm{A}}$ & 0.1 & $1.8^{\mathrm{B}}$ & 0.4 & $2.1^{\mathrm{B}}$ & 0.4 \\
\hline Callus area $\left(\mathrm{mm}^{2}\right)$ & $11^{\mathrm{AB}}$ & 0.8 & $12^{\mathrm{A}}$ & 1.5 & $8^{\mathrm{B}}$ & 0.8 & $9^{\mathrm{AB}}$ & 1.2 \\
\hline Total area $\left(\mathrm{mm}^{2}\right)$ & 17 & 0.7 & 16 & 1.4 & 16 & 1.0 & 17 & 0.6 \\
\hline Cortical density $\left(\mathrm{mg} / \mathrm{cm}^{3}\right)$ & $642^{\mathrm{A}}$ & 12 & $655^{\mathrm{A}}$ & 13 & $722^{\mathrm{B}}$ & 21 & $719^{\mathrm{B}}$ & 13 \\
\hline Callus density $\left(\mathrm{mg} / \mathrm{cm}^{3}\right)$ & 54 & 5 & 58 & 6 & 55 & 4 & 59 & 3 \\
\hline Total density $\left(\mathrm{mg} / \mathrm{cm}^{3}\right)$ & $328^{\mathrm{A}}$ & 15 & $334^{\mathrm{A}}$ & 12 & $420^{\mathrm{B}}$ & 27 & $405^{\mathrm{B}}$ & 24 \\
\hline \multicolumn{9}{|l|}{ Biomechanical analyses } \\
\hline Stiffness $(\mathrm{N} / \mathrm{mm})$ & $85^{\mathrm{A}}$ & 13 & $122^{\mathrm{AB}}$ & 19 & $78^{\mathrm{A}}$ & 15 & $138^{\mathrm{B}}$ & 30 \\
\hline Yield load (N) & 40 & 6 & 53 & 10 & 40 & 12 & 60 & 17 \\
\hline \multicolumn{9}{|l|}{ Microradiography } \\
\hline \multicolumn{9}{|l|}{ Ventromedial aspect } \\
\hline Cortical width (mm) & 0.5 & 0.03 & 0.5 & 0.02 & 0.4 & 0.03 & 0.4 & 0.1 \\
\hline Cortical density (\%) & $99^{\mathrm{A}}$ & 0.2 & $97^{\mathrm{B}}$ & 1 & $100^{\mathrm{A}}$ & 0.1 & $99^{\mathrm{A}}$ & 0.2 \\
\hline Callus width (mm) & $0.3^{\mathrm{A}}$ & 0.03 & $0.3^{\mathrm{A}}$ & 0.02 & $0.4^{\mathrm{B}}$ & 0.1 & $0.4^{\mathrm{AB}}$ & 0.1 \\
\hline Callus density (\%) & $81^{\mathrm{AB}}$ & 3 & $72^{\mathrm{B}}$ & 4 & $84^{\mathrm{A}}$ & 4 & $86^{\mathrm{A}}$ & 5 \\
\hline \multicolumn{9}{|l|}{ Dorsal aspect } \\
\hline Cortical width (mm) & $0.6^{\mathrm{A}}$ & 0.03 & $0.7^{\mathrm{B}}$ & 0.03 & $0.5^{\mathrm{A}}$ & 0.02 & $0.5^{\mathrm{A}}$ & 0.02 \\
\hline Cortical density (\%) & 98 & 1 & 99 & 1 & 100 & 0.1 & 100 & 0.1 \\
\hline Callus width (mm) & $0.7^{\mathrm{AB}}$ & 0.1 & $0.8^{\mathrm{A}}$ & 0.1 & $0.6^{\mathrm{C}}$ & 0.1 & $0.6^{\mathrm{BC}}$ & 0.04 \\
\hline Callus density (\%) & $82^{\mathrm{AB}}$ & 2 & $80^{\mathrm{B}}$ & 3 & $88^{\mathrm{A}}$ & 3 & $87^{\mathrm{a}}$ & 2 \\
\hline \multicolumn{9}{|l|}{ Endosteally } \\
\hline Callus density (\%) & $71^{\mathrm{A}}$ & 3 & $68^{\mathrm{A}}$ & 4 & $70^{\mathrm{A}}$ & 7 & $83^{\mathrm{B}}$ & 3 \\
\hline Trabecular nodes $(n)$ & $14^{\mathrm{A}}$ & 3 & $9^{\mathrm{A}}$ & 2 & $39^{\mathrm{B}}$ & 5 & $44^{\mathrm{B}}$ & 3 \\
\hline Trabecular width $(\mu \mathrm{m})$ & 8 & 3 & 6 & 1 & 8 & 1 & 8 & 0.3 \\
\hline
\end{tabular}

Serum analyses and flat-panel volume computed tomography (fpVCT), biomechanical, and microradiographic image analyses of tibia performed at day 35 after osteotomy at the ventromedial and dorsal aspects and endosteally in ovariectomized or intact rats either vibrated or not vibrated. At least nine replications per treatment group were performed. SEM standard error of the mean, Alp alkaline phosphatase, $O c$ osteocalcin $\mathrm{ABC}$ Between treatment groups means with different superscripts differ $(P<0.05$, test $)$

whereas in ovariectomized rats, it was slightly increased after vibration.

Analyses of fluorochrome-labeled callus revealed no vibration effect on callus formation $(P>0.05)$, whereas lack of estrogen significantly affected periosteal callus formation (Table 2). At the ventromedial aspect, the callus area was reduced in ovariectomized rats compared with intact rats. In contrast, at the dorsal aspect, periosteal callus was larger in ovariectomized rats than in intact rats. The interaction between ovariectomy and vibration had a significant effect on endosteal callus formation. Vibration increased endosteal callus area in intact animals and decreased it in ovariectomized rats. The rate of callus formation increased during the healing regardless of the regions studied, so that within 26-35 days and 18 and 26 days of healing (yellow- and red-stained tissues), more callus was formed per day than within 13 and 18 days of healing (green-stained tissues).

\section{Muscle Analyses}

\section{Respirometric Measurements}

Neither ovariectomy nor vibration had a significant effect on mitochondrial respiration rate among the treatment groups (Table 3). However, the state 3 respiration in 
Fig. 4 Box plot illustrating relative expression levels of a Oc, $\mathbf{b}$ alkaline phosphatase (Alp), c Igf-1, d tartrateresistant acid phosphatase 1 (Trap-1) genes in treatment groups (1) intact vibrated (vib), (2) ovariectomized (Ovx) nonvib, (3) Ovx vib calculated by the $2^{-\Delta \Delta \mathrm{CT}}$ method. Dashed line, expression level in the intact group. Each treatment was conducted with at least nine replications. Medians with different letters differ significantly $(P<0.05$, Dunn test)
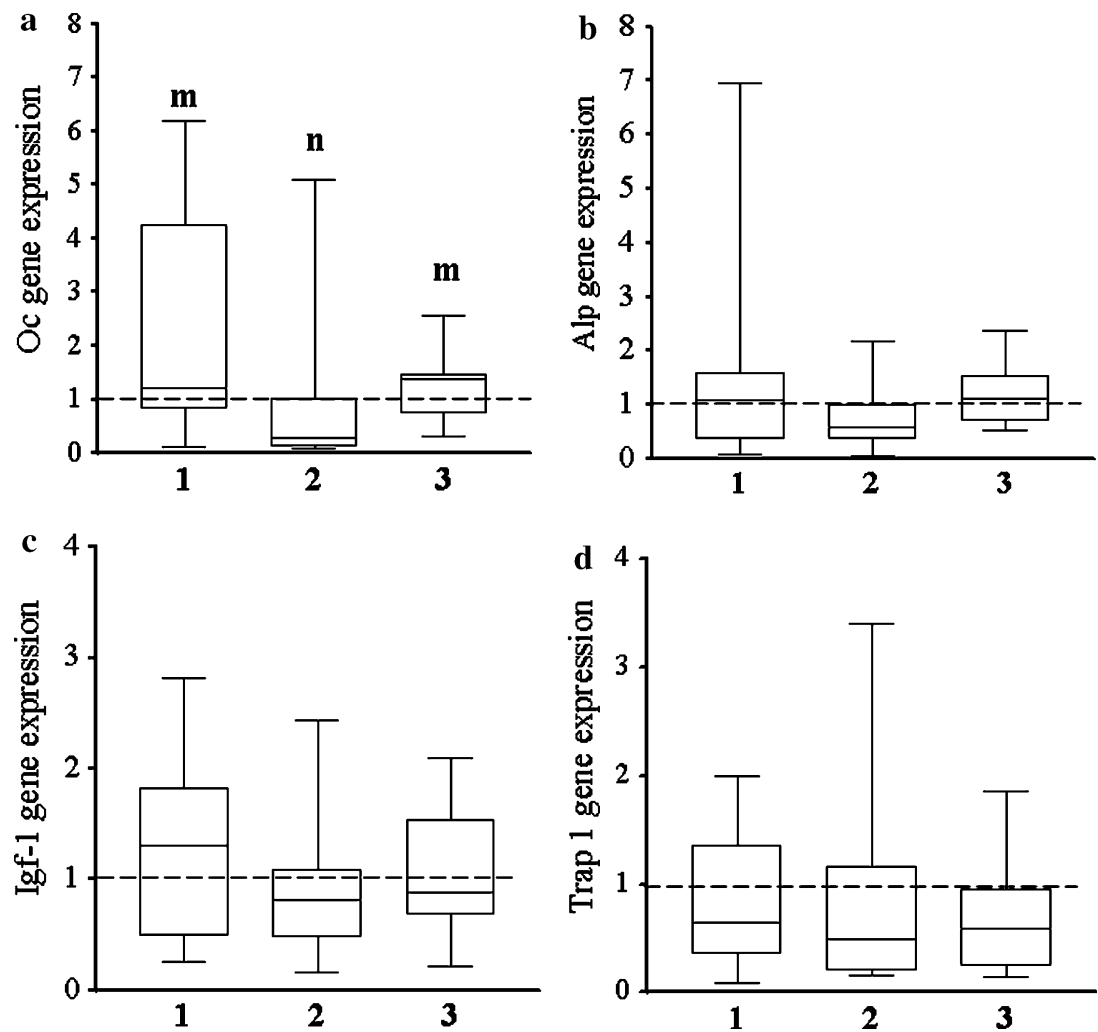

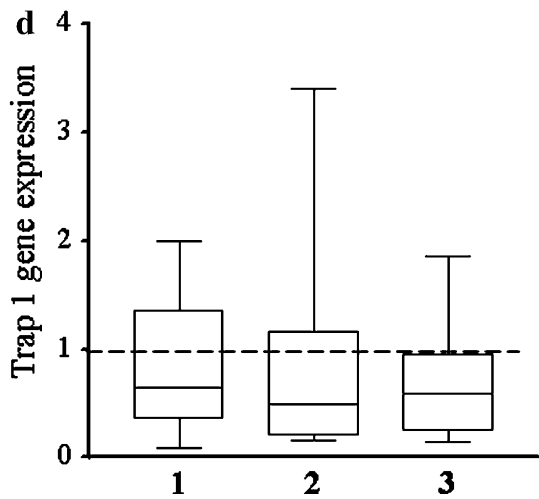

ovariectomized animals was slightly $(P=0.11)$, although not statistically significantly, enhanced after vibration compared to that observed in nonvibrated ovariectomized rats ( 23 vs. $17 \mathrm{pmol} \mathrm{O}_{2} / \mathrm{s} / \mathrm{mg}$ sample weight).

\section{Histological Analyses}

The cross-sectional area of fast-twitch glycolytic fibers and fast-twitch oxidative glycolytic plus slow oxidative in animals exposed to the vibration was larger independent of the investigated muscle (Table 3). Vibrated ovariectomized rats had significantly larger fast-twitch glycolytic fibers in MG compared with those in ovariectomized and intact rats that were nonvibrated (6440 vs. 4829 and $4954 \mu \mathrm{m}^{2}$, respectively). The effect of ovariectomy on fiber size in both muscles was not significant. The fiber type distribution did not differ significantly in ML between the treatment groups (Table 3 ). The capillary density in ML was improved in ovariectomized rats after vibration (Table 3). The interaction between the effects of ovariectomy and vibration significantly affected the capillary density. The vibration enhanced the ratio of capillaries to muscle fiber significantly in ovariectomized rats ( 1.65 vs. 2.13 capillaries/fiber), whereas in intact rats, it remained without significant changes (1.73 vs. 1.65 capillaries/fiber). In MG, density of capillaries did not significantly differ between the treatment groups. However, a slight increase was observed after vibration in both in ovariectomized and intact rats $(P=0.27)$.

\section{Discussion}

In the present study, we report for the first time the effect of the whole-body vibration on bone and muscle during the healing of metaphyseal fracture in ovariectomized and intact rats. The present results showed that a 15-min wholebody vertical vibration $(90 \mathrm{~Hz}, 0.5 \mathrm{~mm}, 4 \times g$ acceleration) starting 5 days after osteotomy and applied twice per day during 30 days improved cortical and callus density at the ventromedial aspect and the increased number of trabecular nodes endosteally in osteopenic rats. In intact rats, the vibration had less effect. Vibration resulted in an increased fiber size in all rats. Furthermore, vibration beneficially affected blood supply and oxidative metabolism in muscle of ovariectomized rats. Biomechanical properties of osteotomized bones were diminished after vibration in all groups, although callus bridging occurred earlier in vibrated ovariectomized rats.

\section{Bone Analyses}

Qualitative analyses of fracture healing showed different vibration effects on the time of the gap bridging, promoting 
Table 2 Rate of callus formation in ovariectomized or intact rats

\begin{tabular}{|c|c|c|c|c|c|c|c|c|}
\hline \multirow[t]{3}{*}{ Osseous callus area $\left(\mu \mathrm{m}^{2}\right)$} & \multicolumn{4}{|c|}{ Ovariectomized } & \multicolumn{4}{|l|}{ Intact } \\
\hline & \multicolumn{2}{|l|}{ Vibrated } & \multicolumn{2}{|c|}{ Not vibrated } & \multicolumn{2}{|l|}{ Vibrated } & \multicolumn{2}{|c|}{ Not vibrated } \\
\hline & Mean & SEM & Mean & SEM & Mean & SEM & Mean & SEM \\
\hline \multicolumn{9}{|l|}{ Ventromedial } \\
\hline Total callus, day 35 & $921^{\mathrm{A}}$ & 166 & $951^{\mathrm{A}}$ & 188 & $1622^{\mathrm{B}}$ & 420 & $983^{\mathrm{AB}}$ & 163 \\
\hline \multicolumn{9}{|l|}{ Callus formation/day } \\
\hline CG & $2^{\mathrm{x}}$ & 1 & $9^{x}$ & 4 & $12^{\mathrm{x}}$ & 4 & $8^{\mathrm{x}}$ & 3 \\
\hline $\mathrm{AC}$ & $14^{\mathrm{Axy}}$ & 8 & $20^{\text {Axy }}$ & 4 & $50^{\text {By }}$ & 17 & $30^{\mathrm{ABy}}$ & 6 \\
\hline $\mathrm{TC}$ & $27^{\mathrm{y}}$ & 7 & $29^{y}$ & 6 & $45^{\mathrm{y}}$ & 16 & $36^{\mathrm{y}}$ & 5 \\
\hline \multicolumn{9}{|l|}{ Dorsal } \\
\hline Total callus, day 35 & $4765^{\mathrm{A}}$ & 670 & $5163^{\mathrm{A}}$ & 517 & $3249^{\mathrm{AB}}$ & 528 & $1986^{\mathrm{B}}$ & 190 \\
\hline \multicolumn{9}{|l|}{ Callus formation/day } \\
\hline CG & $20^{\mathrm{x}}$ & 4 & $24^{\mathrm{x}}$ & 6 & $28^{\mathrm{x}}$ & 6 & $14^{\mathrm{x}}$ & 3 \\
\hline $\mathrm{AC}$ & $168^{\mathrm{ABy}}$ & 31 & $198^{\mathrm{Ay}}$ & 33 & $91^{\text {Bxy }}$ & 19 & $88^{\text {By }}$ & 15 \\
\hline $\mathrm{TC}$ & $127^{\mathrm{Ay}}$ & 23 & $137^{\mathrm{Az}}$ & 22 & $101^{\mathrm{ABy}}$ & 22 & $51^{\text {Bxy }}$ & 8 \\
\hline \multicolumn{9}{|l|}{ Endosteal } \\
\hline Total callus, day 35 & $5780^{\mathrm{A}}$ & 572 & $8511^{\mathrm{B}}$ & 780 & $7347^{\mathrm{AB}}$ & 1154 & $4841^{\mathrm{A}}$ & 601 \\
\hline \multicolumn{9}{|l|}{ Callus formation/day } \\
\hline $\mathrm{CG}$ & $62^{x}$ & 16 & $97^{\mathrm{x}}$ & 28 & $60^{\mathrm{x}}$ & 20 & $53^{x}$ & 17 \\
\hline $\mathrm{AC}$ & $178^{\mathrm{y}}$ & 28 & $175^{\mathrm{y}}$ & 29 & $244^{y}$ & 55 & $166^{\mathrm{y}}$ & 20 \\
\hline $\mathrm{TC}$ & $183^{\mathrm{y}}$ & 27 & $185^{\mathrm{y}}$ & 27 & $185^{\mathrm{y}}$ & 36 & $116^{\mathrm{xy}}$ & 15 \\
\hline Overall callus & $11487^{\mathrm{A}}$ & 980 & $14590^{\mathrm{B}}$ & 1024 & $12201^{\mathrm{AB}}$ & 1100 & $7834^{C}$ & 931 \\
\hline
\end{tabular}

Callus formation in rats at the ventromedial and dorsal aspects, and endosteally determined 35 days after osteotomy on tibia longitudinal sections labeled intravital with calcein green (CG, 13-18 days), alizarin complexone (AC, 18-26 days), and tetracycline (TC, 26-35 days) in ovariectomized or intact rats either vibrated or not vibrated. At least nine replications per treatment group were performed. SEM standard error of the mean

ABC Between treatment group means with different superscripts differ $(P<0.05$, Scheffé test $)$

xyz Between-labeled callus areas $(\mathrm{CG}, \mathrm{AC}, \mathrm{TC})$ within a treatment group at the respective tibia aspect means with different letters differ $(P<0.05$, Scheffé test $)$

it in ovariectomized rats and delaying it in intact rats. Intact and ovariectomized rats responded differently to the vibration treatments. Quantitative analyses confirmed these findings, showing decreased callus area in ovariectomized rats and enlarged area in intact rats due to the vibration. Nevertheless, the biomechanical properties of the osteotomized bones were diminished after vibration in both ovariectomized and intact rats. As reported previously, the callus area does not correlate positively with the biomechanical properties [23]. Callus quality may depend on the noncalcified matrix of the new built-up bone, which we did not assess. Cortical and periosteal callus densities were improved in ovariectomized rats by the vibration reaching the level measured in intact rats. Several researchers investigated the effect of biomechanical stimulation on fracture healing. Some reported increased biomechanical properties and enhanced callus formation and callus mineralization at the fracture site $[16,20,21]$, whereas others found no improvement in fracture healing after mechanical stimulation [18, 19]. However, they used different stimulation devices applying a range of micromevements either directly to a fracture site or indirectly through wholebody vibration. Furthermore, these studies were conducted on intact animals and differed in the type of fractures and osteosyntheses.

When investigating intact, nonfractured bone, a different sensitivity of bone to vibration has been found for ovariectomized and intact animals [11]. Vibration enhanced periosteal apposition and endosteal resorption in ovariectomized rats, whereas no cortical response to the vibration was observed in intact rats [11]. Hormone levels seemed to influence the sensitivity of the bone to the vibration.

The enhanced serum level of Alp in ovariectomized rats endorsed the previous findings [22] and may be explained by the enhanced rate of bone turnover in these rats. Serum Oc level did not change between the groups. The expression level of the Oc gene was observed to be higher in vibrated rats compared to ovariectomized nonvibrated rats, whereas the expression of other genes, such as Alp, Igf-1, and Trap-1, did not differ between the groups. 
Table 3 Respirometric and histological analyses of muscles in ovariectomized and intact rats

\begin{tabular}{|c|c|c|c|c|c|c|c|c|}
\hline \multirow[t]{3}{*}{ Parameter } & \multicolumn{4}{|c|}{ Ovariectomized } & \multicolumn{4}{|l|}{ Intact } \\
\hline & \multicolumn{2}{|c|}{ Vibrated } & \multicolumn{2}{|c|}{ Not vibrated } & \multicolumn{2}{|c|}{ Vibrated } & \multicolumn{2}{|c|}{ Not vibrated } \\
\hline & Mean & SEM & Mean & SEM & Mean & SEM & Mean & SEM \\
\hline \multicolumn{9}{|l|}{ Respirometry (pmol $\mathrm{O}_{2} / \mathrm{s} / \mathrm{mg}$ sample) $\mathrm{MG}$} \\
\hline State 3 & 23 & 2 & 17 & 3 & 19 & 3 & 19 & 3 \\
\hline State 4 & 7 & 1 & 6 & 1 & 6 & 1 & 6 & 2 \\
\hline Respiratory control ratio (state $3 /$ state 4 ) & 5 & 1 & 3 & 0.4 & 4 & 1 & 5 & 1 \\
\hline \multicolumn{9}{|l|}{ Cross-sectional area $\left(\mu \mathrm{m}^{2}\right)$} \\
\hline \multicolumn{9}{|l|}{ MG } \\
\hline FG & $6440^{\mathrm{A}}$ & 486 & $4829^{\mathrm{B}}$ & 448 & $5624^{\mathrm{AB}}$ & 341 & $4954^{\mathrm{B}}$ & 292 \\
\hline $\mathrm{FOG}+\mathrm{SO}$ & 2153 & 138 & 1931 & 170 & 2044 & 114 & 1935 & 209 \\
\hline \multicolumn{9}{|l|}{ ML } \\
\hline FG & 7149 & 249 & 7010 & 554 & 6246 & 362 & 5721 & 703 \\
\hline $\mathrm{FOG}+\mathrm{SO}$ & 2299 & 185 & 2067 & 196 & 2302 & 257 & 1934 & 220 \\
\hline \multicolumn{9}{|l|}{ Capillaries/fiber ratio } \\
\hline MG & 1.66 & 0.2 & 1.62 & 0.1 & 1.62 & 0.2 & 1.52 & 0.1 \\
\hline ML & $2.13^{\mathrm{A}}$ & 0.1 & $1.65^{\mathrm{B}}$ & 0.1 & $1.65^{\mathrm{B}}$ & 0.1 & $1.73^{\mathrm{B}}$ & 0.2 \\
\hline \multicolumn{9}{|l|}{ Fibers ML (\%) } \\
\hline FG & 68 & 2 & 73 & 4 & 67 & 3 & 71 & 2 \\
\hline $\mathrm{FOG}+\mathrm{SO}$ & 32 & 2 & 28 & 4 & 33 & 3 & 29 & 2 \\
\hline
\end{tabular}

Analyses were performed on M. gastrocnemius (MG) and M. longissimus (ML) on day 35 after osteotomy in ovariectomized or intact rats either vibrated or not vibrated. At least nine replications per treatment group were performed. SEM standard error of the mean, $F G$ fast-twitch glycolytic fibers, $F O G+S O$ fast-twitch oxidative glycolytic + slow oxidative

$\mathrm{AB}$ Between treatment groups means with different superscripts differ $(P<0.05$, Scheffé test $)$

Measurement of gene expression levels may not correspond to the resulting levels of protein synthesis [32]. It could be suggested that the changes in the expression level of bone formation gene Oc observed 35 days after osteotomy in vibrated rats may promote further bone synthesis in these animals. The conditions at 35 days after osteotomy corresponded to the reparative stage of fracture healing in rat when osseous callus bridges and stabilizes fractured bone ends [24]. Increased rate of osseous callus formation within 18 and 35 days (red- and yellow-stained callus) indicated intensive calcification at this stage of healing.

fpVCT analysis revealed only the effect of ovariectomy on bone parameters. Estrogen deficiency after ovariectomy over a period of 3 months resulted in a decreased cortical area, cortical density, and number of trabecular nodes, which is in agreement with previous studies. Ovariectomized rats develop severe osteopenia within a few weeks, which is accomplished with significant loss of cortical and trabecular bones [22, 33]. Increased periosteal callus area, also determined histomorphometrically, may be due to the increased periosteal bone apposition reported for ovariectomized rats [34]. Although the callus area was larger and the time of the earliest bridging was not delayed, callus and cortical density were lower compared with those measured in intact rats. These findings confirmed the previous studies that the fracture healing is impaired in osteoporotic organisms [5].

\section{Muscle Analyses}

When we analyzed the muscles, we observed that the vibration stimulated an increase in the cross-sectional area of fibers in both muscles studied, providing benefits to musculature. Similarly, Xie et al. reported a beneficial effect of low-level vibration $(45 \mathrm{~Hz}, 0.3 \times g$ acceleration, 15 min per day) on the mouse musculoskeletal system, observing enlargement of muscle fibers and no fiber type transformation [8]. In our study, the mechanical stimulation of muscle did not lead to the pathological changes in muscle type distribution. The muscle type distribution was determined solely in ML because of the considerable variability in fiber-type populations in MG observed within the muscle [35]. Previous data on the changes in fiber type distribution in response to mechanical stimuli suggested both a shift from fast to slow fibers and vice versa [36, 37]. A shift from slow to fast fiber was reported in rats after chronic high-frequency stimulation of denervated muscle [36]. Fast to slow transformation was observed in denervated electrically stimulated rat muscle [37]. Pigs with malignant hyperthermia display spontaneous muscle 
contractions and greater energy utilization, which leads to work-induced muscle hypertrophy [38]. When the muscle contractions proceed rapidly, oxygen becomes limited, and the muscle will resort to anaerobic glycolysis for energy supply. The larger muscle area and lower capillary density of swine with malignant hyperthermia further contribute to an increased rate of glycolysis [38].

In addition to the enlargement of muscle fibers, we observed significantly enhanced capillary density in ML muscle of ovariectomized rats exposed to the vibration sessions. Vibration evokes reflexive muscle contractions that require an additional energy supply. To satisfy energy demand, additional oxygen is required. This probably causes an increased blood supply to the muscle, thus improving oxygen supply, and may slightly enhance mitochondrial activity in ovariectomized rats. The type and magnitude of the stimuli have been reported to be associated with vascular adaptations at the capillary level, leading to network growth or rarefaction [13, 39]. Murfee et al. reported a significant reduction in the number of blood vessels per muscle fiber in $M$. soleus of adult male mice exposed to the vertical whole-body vibration of $45 \mathrm{~Hz}$ $(0.3 \times g$ acceleration $)$ for $15 \mathrm{~min}$ a day [13]. Physical exercise produced a powerful angiogenic stimulus within the active muscle, which led to a functionally important increase in capillarity [39]. Our results did not match these data, showing no significant changes in capillary density and in oxidative metabolism in intact rats after vibration. The precise mechanisms by which musculoskeletal tissues sense and respond to the vibration have not been identified so far. However, the similarity in the response of muscle and bone to the vibration in ovariectomized and intact rats indicated that hormonal changes contribute to the different musculoskeletal sensitivity to the mechanical stimuli. Just as important, the vibration used in the present study stimulated anabolic effect in both muscle and bone in ovariectomized rats, indicating an overall improvement of musculoskeletal system. Considering the great importance of muscle and bone quality in the prevention of falls and fractures in patients with osteoporosis, whole-body vibration may provide a nonpharmacological way to improve the musculoskeletal system.

Previous studies have indicated that estrogen is able to enhance mitochondrial activity and stimulate angiogenesis in skeletal muscle [24, 40]. It has been reported that ovariectomized rats had larger muscle fibers than those supplemented with estrogen [41]. Kadi et al. observed fast to slow fiber shift in rat muscle after ovariectomy that was associated with a decreased level of physical activity [42]. However, in our study, we did not find any significant differences in muscle fiber size, mitochondrial activity, capillary density, and fiber-type distribution between ovariectomized and intact rats. Considering that all rats underwent bilateral tibia osteotomy, it is possible that regenerative processes were activated in the rats, reducing the effect of ovariectomy on the muscle, although the bone quality remained impaired by estrogen deficiency. It is known that changes in muscle seemed to occur more rapidly than did the bone after onset of menopause [43]. Some previous studies showing the effect of estrogen on muscle parameters were performed in estrogen-supplemented ovariectomized animals and not in intact rats, as in our study.

\section{Animal Model}

The ovariectomized rat has been widely used as a model of postmenopausal osteoporosis [22]. The success of ovariectomy has been confirmed by the atrophied uterine horns that were observed in ovariectomized animals. Body weight increased in all animals during first 10 weeks. Among other factors, the general growth of the 3-month old rats may have been responsible for this [44]. However, the weight gain was different between the groups. Because of the ovariectomy-induced lack of hormones, these animals weighed much more than intact animals throughout the experiment, although food consumption did not differ between the treatment groups. Increased body weight after ovariectomy is a known phenomenon in rat [24]. Vibration applied in the present study affected neither body weight nor food intake. This indicates that the noninvasive wholebody vibration was not stressful for the rats.

The limitations of the present study are the application of one vibration regime and the investigation of fracture healing and muscle function at one point of time. Because studies on the effect of whole-body vibration on metaphyseal fracture healing in rat are lacking, the vibration frequency of $90 \mathrm{~Hz}$ was chosen because of its anabolic effect on nonfractured bone observed in ovariectomized and intact rats $[7,30]$. The time point was set at 35 days after osteotomy, enabling analyses of callus formation before callus resorption occurred [24].

\section{Conclusion}

The vibration had different effects on ovariectomized and intact rats, improving some bone and muscle parameters in ovariectomized rats and having less effect in intact rats. The present findings suggest that whole-body vibration can be an effective substitute for estrogen for osteoporotic organisms. However, the chosen vibration regimen seemed unfavorable for fracture healing because the biomechanical properties of tibia were diminished. Perhaps the intensive biomechanical stimulation $(90 \mathrm{~Hz}$ twice a day) was too much, thus disturbing calcification of the callus matrix and 
diminishing its stiffness. The present finding is of significant concern when applying this stimulation to improve fracture healing. To put it in perspective, noninvasive whole-body vibration could be an option to facilitate mobilization and bone healing in patients with fractures. However, further studies are required to investigate the effect of different vibration regimens and to discover the best combination of amplitude, frequency, and duration for fracture healing. Bone healing should be evaluated at several time points to follow up on complete healing. Continuous monitoring at different time points of bone and muscle metabolism (gene expression, and serum and muscle enzyme analyses) may help our understanding of how different vibrations affect the musculoskeletal system. Furthermore, the role of estrogen on the bone healing in the absence or presence of vibratory stimuli should be evaluated.

Acknowledgments The present study was supported by the German Research Foundation (DFG, STU 478/3-1). The authors are grateful to the colleagues F. Kauer, R. Castro-Machguth, A. Witt, and R. Wigger for their help.

Open Access This article is distributed under the terms of the Creative Commons Attribution Noncommercial License which permits any noncommercial use, distribution, and reproduction in any medium, provided the original author(s) and source are credited.

\section{References}

1. Kiratli BJ (1996) Immobilization osteopenia. In: Marcus R, Feldman D, Kelsey J (eds) Osteoporosis. Academic Press, San Diego, pp 833-853

2. Jee WS, Ma Y (1999) Animal models of immobilization osteopenia. Morphologie 83:25-34

3. Stuermer KM, Rack TH, Kauer F (1980) Intravitale Bewegungsmessung bei der Frakturheilung. Hefte Unfallheilkd 212:489-498

4. Yamaji T, Ando K, Wolf S, Augat P, Claes L (2001) The effect of micromovement in callus formation. J Orthop Sci 6:571-575

5. Namkung-Matthai H, Appleyard R, Jansen J, Hao Lin J, Maastricht S, Swain M, Mason RS, Murrell GA, Diwan AD, Diamond $T$ (2001) Osteoporosis influences the early period of fracture healing in a rat osteoporotic model. Bone 28:80-86

6. Sitnick M, Foley AM, Brown M, Spangenburg EE (2006) Ovariectomy prevents the recovery of atrophied gastocnemius skeletal muscle mass. J Appl Physiol 100:286-293

7. Judex S, Lei X, Han D, Rubin C (2007) Low-magnitude mechanical signals that stimulate bone formation in the ovariectomized rat are dependent on the applied frequency but not on the strain magnitude. J Biomech 40:1333-1339

8. Xie L, Rubin C, Judex S (2008) Enhancement of the adolescent murine musculoskeletal system using low-level mechanical vibrations. J Appl Physiol 104:1056-1062

9. Verschueren SMP, Roelants M, Delecluse C, Swinnen S, Vanderschueren Boonen S (2004) Effect of 6-month whole body vibration training on hip density, muscle strength, and postural control in postmenopausal women: a randomized controlled pilot study. J Bone Miner Res 19:352-359
10. Oxlund BS, Ørtoft G, Andreassen TT, Oxlund H (2003) Lowintensity, high-frequency vibration appears to prevent the decrease in strength of the femur and tibia associated with ovariectomy of adult rats. Bone 32:69-77

11. Rubinacci A, Marenzana M, Cavani F, Colasante F, Villa I, Willnecker J, Moro GL, Spreafico LP, Ferretti M, Guidobono F, Marotti G (2008) Ovariectomy sensitizes rat cortical bone to whole-body vibration. Calcif Tissue Int 82:316-326

12. Chao EYS, Inoue N (2003) Biophysical stimulation of bone fracture repair, regeneration and remodelling. Eur Cell Mater 6:72-85

13. Murfee WL, Hammett LA, Evans C, Xie L, Squire M, Rubin C, Judex S, Skalak TC (2005) High-frequency, low-magnitude vibrations suppress the number of blood vessels per muscle fiber in mouse soleus muscle. J Appl Physiol 98:2376-2380

14. Matsushita T, Kurokawa T (1998) Comparison of cyclic compression, cyclic distraction and rigid fixation. Bone healing in rabits. Acta Orthop Scand 69:95-98

15. Goodship AE, Lawes TJ, Rubin CT (2009) Low-magnitude highfrequency mechanical signals accelerate and augument endochondral bone repair: preliminary evidence of efficacy. J Orthop Res 27:922-930

16. Shadmehr A, Esteki A, Oliaie GR, Torkaman G, Sabbaghian A (2009) Augumentation of bone healing by specific frequency and amplitude compressive strains. Orthopedics 32:173

17. Wolf S, Janousek A, Pfeil J, Veith W, Haas F, Duda G, Claes L (1998) The effects of external mechanical stimulation on the healing of diaphyseal osteotomies fixed by flexible external fixation. Clin Biomech 13:359-364

18. Augat P, Merk J, Wolf S, Claes L (2001) Mechanical stimulation by external application of cyclic tensile strains does not effectively enhance bone healing. J Orthop Trauma 15:54-60

19. Wolf S, Augat P, Eckert-Hübner K, Laule A, Krischak GD, Claes LE (2001) Effects of high-frequency, low-magnitude mechanical stimulus on bone healing. Clin Orthop Relat Res 385:192-198

20. Usui Y, Zerwekh JE, Vanharanta H, Ashman RB, Mooney V (1989) Different effects of mechanical vibration on bone ingrowth into porous hydroxyapatite and fracture healing in a rabbit model. J Orthopaed Res 7:559-567

21. Leung KS, Shi HF, Cheung WH, Qin L, Ng WK, Tam KF, Tang N (2008) Low-magnitude high-frequency vibration accelerates callus formation, mineralization, and fracture healing in rats. $\mathrm{J}$ Orthopaed Res 27:458-465

22. Kalu DN (1991) The ovariectomized rat model of postmenopausal bone loss. Bone Miner 15:175-192

23. Stuermer EK, Sehmisch S, Rack T, Wenda E, Seidlova-Wuttke D, Tezval M, Wuttke W, Frosch KH, Stuermer KM (2010) Estrogen and raloxifene improve metaphyseal fracture healing in the early phase of osteoporosis. A new fracture-healing model at the tibia in rat. Langenbecks Arch Surg 395:163-172

24. Komrakova M, Werner C, Wicke M, Sehmisch S, Tezval M, Stuermer KM, Stuermer EK (2009) Effect of daidzein, 4-methylbenzylidene camphor or estrogen on gastrocnemius muscle of osteoporotic rats undergoing tibia healing period. J Endocrinol 201:253-262

25. Rahn DA (1976) The fluorochrome sequence labeling of the bone. Nova Acta Leopold 44:249-255

26. Seidlová-Wuttke D, Stuermer KM, Stuermer EK, Sehmisch S, Wuttke W (2006) Contrasting effects of estradiol, testosterone and of black cohosh extract on density, mechanical properties and expression of several genes in the metaphysic of the tibia and on fat tissue of orchidectomized rats. Maturitas 55:S64-S74

27. Livak KJ, Schmittgen TD (2001) Analysis of relative gene expression data using real-time quantitative PCR and the 2$\Delta \Delta C T$ method. Methods 25:402-408 
28. Missbach-Guentner J, Dullin C, Zientkowska M, DomeyerMissbach M, Kimmina S, Obenauer S, Kauer F, Stühmer W, Grabbe E, Vogel WF, Alves F (2007) Flat-panel detector-based volume computed tomography: a novel 3D imaging technique to monitor osteolytic bone lesions in a mouse tumor metastasis model. Neoplasia 9:755-765

29. Stürmer EK, Seidlová-Wuttke D, Sehmisch S, Rack T, Wille J, Frosch KH, Wuttke W, Stürmer KM (2006) Standardized bending and breaking test for the normal and osteoporotic metaphyseal tibias of the rat: effect of estradiol, testosterone, and raloxifene. J Bone Miner Res 21:89-96

30. Sehmisch S, Galal R, Kolios L, Tezval M, Dullin C, Zimmer S, Stuermer KM, Stuermer EK (2009) Effects of low-magnitude, high-frequency mechanical stimulation in the rat osteopenia model. Osteoporos Int 20:1999-2008

31. Peter JB, Barnard RJ, Edgerton VR, Gillespie CA, Stempel KE (1972) Metabolic profiles of the three fiber types of skeletal muscle in guinea pigs and rabbits. Biochemistry 11:26272633

32. Meyer RA, Meyer MH, Tenholder M, Wondracek S, Wasserman $R$, Garges P (2003) Gene expression in older rats with delayed union of femoral fractures. J Bone Joint Surg 85A(7):1243-1254

33. Wronski TJ, Lowry PL, Walsch CC, Ignaszewski LA (1985) Skeletal alternations in ovariectomized rats. Calcif Tissue Int 37:324-328

34. Turner RT, Vandersteenhoven JJ, Bell NH (1987) The effects of ovariectomy and 17 beta-estradiol on cortical bone histomorphometry in growing rats. J Bone Miner Res 2:115-122

35. Armstrong RB, Phelps RO (1984) Muscle fiber type composition of the rat hindlimb. Am J Anat 171:259-272
36. Gorza L, Gundersen K, Lömo T, Schiaffino S, Westgaard RH (1988) Slow-to-fast transformation of denervated soleus muscles by chronic high-frequency stimulation in the rat. J Physiol (Lond) 398:177-189

37. Windisch A, Gundersen K, Szabolcs MJ, Gruber H, Lomo T (1988) Fast to slow transformation of denervated and electrically stimulated rat muscle. J Physiol 510:623-632

38. Scheffler TL, Gerrard DE (2007) Mechanisms controlling pork quality development: the biochemistry controlling postmortem energy metabolism. Meat Sci 77:7-16

39. Prior BM, Lloyd PG, Yang HT, Terjung RL (2003) Exerciseinduced vascular remodelling. Exerc Sport Sci Rev 31:26-33

40. Kyriakides ZS, Petinakis P, Kaklamanis L, Sbarouni E, Karayannakos P, Iliopoulos D, Dontas I, Kremastinos DT (2001) Intramuscular administration of estrogen may promote angiogenesis and perfusion in a rabbit model of chronic limb ischemia. Cardiovasc Res 49:626-633

41. Kobori M, Yamamuro T (1989) Effects of gonadectomy and estrogen administration on rat skeletal muscle. Clin Orthop 243:306-311

42. Kadi F, Karlsson C, Larsson B, Eriksson J, Larval M, Billig H, Jonsdottir IH (2002) The effects of physical activity and estrogen treatment on rat fast and slow skeletal muscles following ovariectomy. J Muscle Res Cell Motil 23:335-339

43. Marcus R, Greensdale G, Blunt BA, Bush TL, Sherman S, Sherwin R, Wahner H, Wells B (1994) Correlates of bone mineral density in the postmenopausal estrogen/progestin intervention trial. J Bone Miner Res 9:1467-1476

44. Berg BN, Harmison CR (1957) Growth, disease, and aging in the rat. J Gerontol 2:370-377 